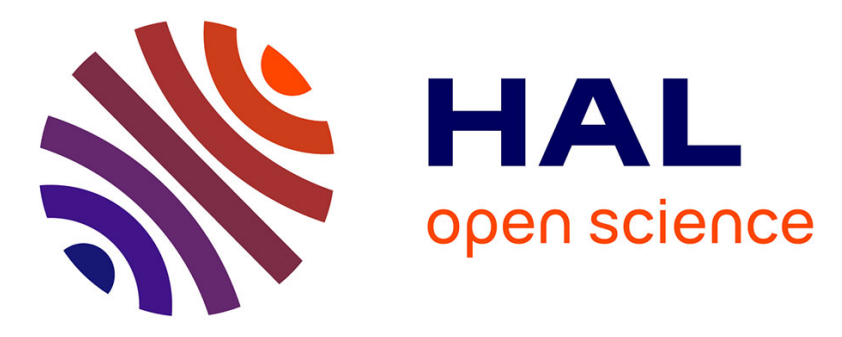

\title{
Modeling of light transmission under heterogeneous forest canopy: an appraisal of the effect of the precision level of crown description
}

\author{
David da Silva, Philippe Balandier, Frédéric Boudon, André Marquier, \\ Christophe Godin
}

\section{To cite this version:}

David da Silva, Philippe Balandier, Frédéric Boudon, André Marquier, Christophe Godin. Modeling of light transmission under heterogeneous forest canopy: an appraisal of the effect of the precision level of crown description. Annals of Forest Science, 2012, 69 (2), pp.181-193. 10.1007/s13595-011-0139-2 . hal-00828845

\section{HAL Id: hal-00828845 \\ https://hal.inria.fr/hal-00828845}

Submitted on 7 Jan 2015

HAL is a multi-disciplinary open access archive for the deposit and dissemination of scientific research documents, whether they are published or not. The documents may come from teaching and research institutions in France or abroad, or from public or private research centers.
L'archive ouverte pluridisciplinaire HAL, est destinée au dépôt et à la diffusion de documents scientifiques de niveau recherche, publiés ou non, émanant des établissements d'enseignement et de recherche français ou étrangers, des laboratoires publics ou privés.

$$
\text { Copyright }
$$


$1 \quad$ Modeling of light transmission under heterogeneous

2 forest canopy: an appraisal of the effect of the precision

3

\section{level of crown description}

4

$5 \quad$ Number of characters: 51433

6 Number of tables: 3

7 Number of figures: 4

8

9 Keywords: Light modeling, Forest, Mixed stand, Uneven-aged stand, Canopy description, Multi-scale

10 David Da Silva \& Philippe Balandier \& Frédéric Boudon \& André Marquier \& Christophe Godin Handling Editor: Erwin Dreyer D. Da Silva ( * ) Department of Plant Sciences, University of California D 


\section{Abstract}

- Context: Light availability in forest understorey is essential for many processes, it is therefore a valuable information regarding forest management. However its estimation is often difficult and direct measurements are tedious. Models can be used to compute understorey light but they often require a lot of field data to accurately predict light distribution, particularly in the case of heterogeneous canopies.

- Aims: The influence of the precision level of crown description was studied with a model, M $\mu$ SLIM, that can be used with both detailed and coarse parametrization with the aim of reducing to a minimum field data requirements.

- Methods: We analyzed the deterioration of the prediction quality of light distribution to the reduction of inputs by comparing simulations to transmitted light measurements in forests of increasing complexity in three different locations.

- Results: With a full set of parameters to describe the tree crown (i.e. crown extension in at least 8 directions, crown height and length), the model accurately simulated the light distribution. Simplifying crown description by a geometric shape with a mean radius of crown extension led to deteriorated but acceptable light distributions. Allometric relationships used to calculate crown extension from trunk DBH seriously reduced light 


\section{Introduction}

35 Light in forest understorey is a fundamental resource driving many processes

36 related for example to regeneration growth, vegetation cover and composition,

37 and animal habitat (Balandier et al. 2009). Light quality is fundamental for

38 morphogenetic processes, whereas light quantity drives processes linked to carbon

39 acquisition. In this article only light quantity is considered.

40 For a long time light in forest has only been considered as a factor controlling tree

41 growth, especially in the case of regular even-aged stands in the temperate area. In

42 that context, tree density has been managed to get a very dark understorey with

43 often a bare soil, sign that trees absorbed the maximum of radiations (Perrin

44 1963). Nowadays a silviculture closer to nature (also named continuous cover

45 forestry) with natural regeneration is promoted or rediscovered (Hale 2009).

46 Irregular uneven-aged stands often with mixed species are managed with partial

47 cutting to create gaps in the forest canopy. These gaps favor some patch of light

48 essential to tree regeneration but also promote the development of understorey

49 vegetation that can compete with young trees and compromise forest dynamic

50 (Balandier et al. 2009). Under these conditions, in order to sustain young tree

51 growth while avoiding too dense understorey vegetation, it is essential to

52 proportion light by the size of the gaps (Gaudio et al. 2011). 
54 However estimating light quantity in forest understorey is not so easy (Lieffers et 55 al. 1999). On one hand, visual assessment are strongly biased by the 56 meteorological conditions, the hour of the day and the operator himself. On the

57 other hand, direct measurements by sensors are often tedious, expensive, require 58 technical competences, and their results also depend on the meteorological 59 conditions and the solar pathway on the day of measurement (Pukkala et al. 60 1993).

62 Since the pioneer work of Monsi and Saeki (1953), many models simulating light 63 interception and transmission by plant canopies have been developed (see Myneni 64 et al., 1989 and Sillon and Puech, 1994 for reviews) and offer an operative 65 alternative. They are based on, either statistical relationships between vegetation 66 characteristics such as cover, leaf area or leaf area index (LAI) and light 67 transmission, or explicit description of the canopy topology and geometry as 68 elements intercepting light. When forest canopy is homogeneous, i.e. even-aged 69 pure regular stands, statistical models predict mean light quantity in forest 70 understorey with an acceptable accuracy (Balandier et al. 2006b; Hale et al. 2009;

71 Sonohat et al., 2004). However prediction quality of that type of models decreases

72 drastically with the increase in heterogeneity of the stand structure (Balandier et 73 al. 2010). In particular in irregular uneven stands a statistical mean has no sense 74 because it does not reveal the light distribution between understorey and gaps 
75 which is of most interest for the forester. With that information, local light

76 availability to favor tree regeneration, plant biodiversity, or animal habitat for

77 example can be estimated (Balandier et al. 2006a).

79 In that case, complex models with an explicit 3D-description of elements 80 intercepting light give more accurate results. The approach of these models 81 usually involve the use of numerous tracing (sun) rays coming from different 82 points in the sky to a particular point within the stand and compute transmission 83 along those rays taking into account foliage characteristics, thus generating a 84 detailed 2D-map of light availability in the understorey (Cescatti 1997; Brunner 85 1998; Stadt and Lieffers 2000; Courbeau et al. 2003; Mariscal et al. 2004 ). 86 However these models require abundant field measurements to parametrize them.

87 These measurements, like a map of tree location on the site, the 3D-geometry of 88 each tree crown with information on leaf area density, distribution and clumping 89 inside the crown, are tedious and often difficult to obtain. Moreover, for 90 management purpose, a detailed 2D-map of light availability in the understorey is 91 not always required. For the forest manager an histogram of light transmittance at 92 the plot level (i.e. percentage of soil per class of transmitted light, without 93 knowing the spatial distribution of the light transmitance) can be sufficient.

94 From a scientific point of view, there is a need to identify the key elements of 95 plant architecture that are necessary to consider to correctly predicts different 96 processes including light transmission, at different scales. Indeed, "simplifications 
97 which are unacceptable at a detailed level of representation can become

98 acceptable at a more integrated level (Tardieu, 2010). However the difficulty is to

99 define what the key elements are and the emerging properties linked to them

100 related to such or such a scale of description.

101

102 Muslim is a model especially designed to bridge the gap between the statistical

103 and explicit approach. It can be seen as a multi-scale mixed model in the sense

104 that the light interception estimation method can be changed at each scale (Da

105 Silva et al. 2008). Furthermore, M $\mu$ slim was designed to to work with any type of

106 envelope encompassing the vegetation for which light attenuation is to be

107 computed, thus allowing precise description of complex canopy and crown

108 shapes. This feature allowed to overcome the restriction to analytically defined

109 envelope used in other models (Norman and Welles, 1983; Cescatti 1997).

110 Although it was initially dedicated to study light interception by isolated trees, its

111 versatile design and multi-scale approach made its adaptation to use at canopy

112 scale easy. Therefore we were able to use it to analyse how the deterioration of the

113 canopy description influences the accuracy of the light histogram simulated at the

114 plot level. Our objective was to specify the minimum field data needed by the

115 model to be able to accurately simulate the light distribution. Our experimental

116 design was as follow, 1) compare the simulated light distribution using the more

117 detailed description of the canopy with measured data on the field, 2) analyze the

118 statistical distance between histograms simulated for decreasing levels of 
119 description and measured data.

\section{Material and Method}

\section{Forest sites and plots}

123 Three forest sites located in France with a total of 8 plots were used with

124 increasing canopy structure complexity; 5 monospecific even-aged stands made

125 up from Pinus sylvestris L. or Pinus nigra Arnold, 2 mixed Quercus petraea L. -

126 Pinus sylvestris L. uneven-aged stands and 1 mixed Abies alba - Pinus sylvestris

127 - Fagus sylvatica L. uneven-aged stands (Tab.1).

128 The Scots pine stands are located in the Chaîne des Puys, a mid-elevation volcanic

129 mountain range at a place named Fontfreyde (Tab. 1). The elevation is $900 \mathrm{~m}$

130 a.s.l., mean annual rainfall is about $820 \mathrm{~mm}$, and mean annual temperature is

131 about $7^{\circ} \mathrm{C}$. The soil is a volcanic brown soil at $\mathrm{pH} 6.0$ with no mineral deficiency.

132 The pines were 30 to 50 -year-old at time of measurement, with a density ranging

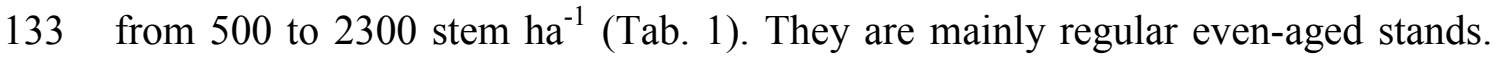

134 Some other species can be locally present such as Betula pendula.

135 The mixed oak - pine stands are located in the National forest of Orleans, in the

136 sub-part named Lorris. They are typical stands of temperate plain forest with a

137 mild climate (mean annual rainfall $720 \mathrm{~mm}$; mean annual temperature $10.8^{\circ} \mathrm{C}$ )

138 and acidic sandy poor soils temporarily flooded in winter or spring. They are

139 irregular uneven-aged stands. Median $\mathrm{DBH}$ are about $18 \mathrm{~cm}$, whereas some

140 individuals, in particular of Scots pine, can reach $70 \mathrm{~cm}$. Some other species are 
141 locally present such as Betula sp., Carpinus betulus, Sorbus torminalis, Malus

142 sylvestris or Pyrus communis.

143 The third site is located in the South-East of France, in the mountainous area

144 named Mont Ventoux. One plot, VentouxC7, on the southern side of the

145 mountain, $1100 \mathrm{~m}$ a.s.l., is an old even-aged Pinus nigra plantation, almost

146 regular, with some pine and beech seedlings, on a flat area. The second plot,

147 Ventoux34, on the northern side of the mountain, $1400 \mathrm{~m}$ a.s.1., is a mixed

148 irregular stand with advanced regeneration of Abies alba and Fagus sylvatica with

149 some taller saplings almost reaching the open overstorey of old planted Pinus

150 sylvestris, and some other scattered species (Sorbus aria, Acer opalus ...). The

151 climate is mountainous with Mediterranean influences (mean annual temperature

152 is $8.6^{\circ} \mathrm{C}$ and $6.7^{\circ} \mathrm{C}$, and mean annual rainfall is $1080 \mathrm{~mm}$ and $1360 \mathrm{~mm}$, for

153 VentouxC7 and Ventoux34, respectively). The soils are a calcosol (VentouxC7)

154 and a colluvial rendosol (Ventoux34), $20 \mathrm{~cm}$ and $50 \mathrm{~cm}$ deep in average,

155 respectively, with a high stone content (50\% and $75 \%$ resp.), both with a silty clay

156 texture, on a fissured limestone. The median DBHs approximate 38 and $15 \mathrm{~cm}$

157 (for the first and the second plot respectively) with some trees reaching $50 \mathrm{~cm}$.

\section{2. Canopy structure measurements}

160 All trees in a square area, the experimental unit (Fig.1a), of size approximately

161 three times the height of dominant trees, were identified (species), located by their

$162 \mathrm{x}, \mathrm{y}$ coordinates, and measured for their total height and Diameter at Breast Height 
163 (DBH). Top and bottom crown heights were also measured. Lateral crown extents

164 was assessed by visually projecting to the soil its characteristic points (i.e. the

165 points that better describe the crown irregularities) in, at least, four directions, but

166 sometimes with more than 8 directions when necessary. The azimuth and distance

167 of those points from trunk were then measured (Fig.1b and c).

168

\section{Light measurements}

170 The light measurements were conducted in the central zone of the experimental

171 unit. The surrounding zone where dendrometric measures were done acts as a

172 buffer zone accounting for the attenuation of the encompassing forest (Fig.1a.).

173 The light measurements were achieved using a square grid composed of 64 PAR

174 sensors, namely Solems PAR/CBE 80 sensors. Each sensor was separated from its

175 neighbour in both direction by 2 to $3.5 \mathrm{~m}$ depending on the considered plot (i.e.

176 depending on the mean size of the trees). This distance was set by previous

177 computation based on geostatistics (data not shown) and so that two contiguous

178 measurements (points) can be considered as independent. Light measurements

179 were done for each plot during $24 \mathrm{~h}$ during summer to take the full sun course into

180 account. One additional PAR sensor, Sunshine sensor BF2, was positioned

181 outside of the experimental unit in full light to measure global (total) and diffuse

182 incident radiation. This extra sensor uses an array of photodiodes with a

183 computer-generated shading pattern to measure incident solar radiation and the

$184 \mathrm{D} / \mathrm{G}$ ratio, i.e. the diffuse to global radiation ratio. Transmittance for each point in 
185 the understorey is then computed as the ratio of light measured in the understorey

186 divided by the incident value. The $\mathrm{D} / \mathrm{G}$ ratio is taken into account for simulating

187 the transmittance with the model.

188

\section{Model description}

190 Estimation of light transmission is a process that requires first the stand

191 reconstruction. Then, the light attenuation within each crown must be defined so

192 that the light model can compute the transmittance under the entire canopy.

- Canopy reconstruction

194 From the dendrometric measurements on the field, a mockup of the stand is

195 generated. This generation involves the construction of a crown (and trunk) for

196 each tree of the stand and its positioning. To reconstruct the 3D envelopes of the

197 trees from the field measurements, we used the PlantGL library (Pradal et al.

198 2008). This library contains several geometric models, including different types of

199 envelopes and algorithms to reconstruct the geometry of plants at different scales.

200 In this work, we used the skinned surface which is a generalization of surface of

201 revolution with varying profiles being interpolated. The envelope of a skinned

202 hull is a closed skinned surface which interpolates a set of profiles $\left\{\mathrm{P}_{\mathrm{k}}, \mathrm{k}=0, \ldots\right.$,

$203 \mathrm{~K}\}$ positioned at angle $\left\{\alpha_{\mathrm{k}}, \mathrm{k}=0, \ldots, \mathrm{K}\right\}$ around the $\mathrm{z}$ axis, where $\mathrm{K}$ is the 204 number of profiles used to generate the skinned surface. This surface is thus built 205 from any number of profiles with associated direction. In such case, a profile is 206 supposed to pass through common top and bottom points and at an intermediate 
207 point of maximum radius, i.e. the height of the crown maximum width. Two 208 shape factors, $\mathrm{C}_{\mathrm{T}}$ and $\mathrm{C}_{\mathrm{B}}$, were used to describe the shape of the profiles above 209 and below the maximum width. Mathematically, two quarters of super-ellipse of 210 degree $C_{T}$ and $C_{B}$ were used to define the top and bottom part of the profiles, see 211 Da Silva et al. (2008) for details. Note that our envelopes can be viewed as 212 extension of Cescatti (1997)'s asymmetric hull with profiles in any direction 213 instead of the restricted cardinal directions. Flexibility of our model enabled us to 214 measure the most adequate profiles in case of irregular crowns. The 3D envelope 215 of a tree was thus obtained using a skinned surface generated from profiles 216 defined from an angle, a maximum width and its associated height and two shapes 217 factors. The trunk of the tree was represented as a cylinder of DBH diameter, the 218 height of the cylinder being set to the crown bottom height. The 3D representation 219 of an experimental unit is presented in Fig.2.

$220 \quad \circ$ Estimation of light transmission

221 The light transmission under such reconstructed stand was computed using the 222 multi-scale light interception model (M 223 (2008). For each direction of incoming light, a set of beams was cast and the 224 attenuation of each beam through the canopy was estimated. In the present study, 225 the model was a simple two-scale model where the porous envelopes of crowns 226 constituted the finest scale and the stand, the coarser scale. In replacement of the 227 delicate estimation of leaf area density (LAD), a global opacity value, $\mathrm{p}_{\mathrm{gl}}$, was 228 associated with each envelope of the reconstructed stand, the trunks were 
229 considered opaque organs, thus their opacity was 1. Crowns global opacity were

230 estimated from field photographs shooting vertically different parts of the crown.

231 Each image was digitized, segmented to black and white and then the pixels were

232 counted using PiafPhotem software (Adam et al., 2006). The ratio of black pixels

233 to the total number of pixels yielded the opacity of the crown while the ratio of

234 white pixels to the total number of pixels produced the crown porosity, hence

235 porosity $=1$ - opacity. However, the opacity of each individual crown was not

236 directly estimated using this method because the segmentation procedure still

237 required human intervention. Instead a global opacity value per species was

238 estimated over a sample of pictures (Tab.1). MuSLIM allowed then to compute

239 the light transmission of the canopy by considering the light attenuation of each

240 beam. The light attenuation for one beam is computed according to the opacities

241 of the crowns encountered along its trajectory and according to the path length

242 within each of these crowns. The porosity expression that takes the beam

243 travelling distance into account is related to $G$ (Chen and Black 1992; Ross 1981;

244 Stenberg 2006), the extinction coefficient that depends on light direction and leaf

245 inclination distribution, and $L A D$, the leaf area density. It can be expressed as:

$$
p=\frac{1}{\beta} \sum_{b \in B}\left(1-\exp \left(-G \cdot L A D . l_{b}\right)\right)
$$

246 where $B$ is the set of beams $b, \beta$ is its cardinality, and $l_{b}$ is the path length of the 247 beam into the crown. To take this distance into account, we thus need to 248 determine the quantity G.LAD. 
249 The global opacity value can be regarded as the result of opacity estimation using

250 Beer-Lambert law in a infinite horizontally homogeneous layer:

$$
p_{g l}=1-\exp (-G \cdot L A I) .
$$

251 This relation yields an expression for G.LAI, where $L A I$ is the leaf area index. In 252 the case of crowns with a finite volume, $V$, the usual definition of $L A I$ can be 253 extended to be expressed as a function of the total leaf area, TLA, and the 254 projected envelope area, PEA (Sinoquet et al. 2007)

$$
L A I=\frac{T L A}{P E A},
$$

255 and since $L A D$ is the ratio of total leaf area to crown volume,

$$
L A D=\frac{T L A}{V} .
$$

256 We can express G.LAD as

$$
G \cdot L A D=\frac{G \cdot L A I \cdot P E A}{V}=\frac{-\log \left(1-p_{g l}\right) \cdot P E A}{V} .
$$

257 Using this G.LAD value with equation (1) naturally leads to a smaller envelope 258 opacity value than $\mathrm{p}_{\mathrm{gl}}$. This is due to the fact that the negative exponential of a 259 mean value is less than the mean of negative exponential values. Therefore a 260 numerical approximation was carried out using the value from equation (5) as the 261 starting value to speed-up convergence. The process stopped when the opacity 262 computed using equation (1) was equal to the global opacity within a user-defined 263 error, $\varepsilon$. This G.LAD approximation was done once for each crown and for each 
264 direction, and stored for further usage. The crown opacity for each beam, $p_{b}$, was

265 then computed using the expression

$$
p_{b}=1-\exp \left(-G \cdot L A D \cdot l_{b}\right)
$$

266 The light transmission of the canopy along one direction was estimated by 267 computing, for each beam, its total opacity resulting from its travelling through 268 the canopy, i.e. possibly going through multiple crowns, see Da Silva et al. (2008) 269 for algorithmic and computational details. Experimental conditions were 270 simulated by using two sets of incoming radiation directions. The first set, for 271 diffuse light, discretized the sky hemisphere in 46 solid angle sectors of equal 272 area, according to the Turtle sky proposed by Den Dulk (1989). The directions 273 used were the central direction of each solid angle sector. The second set, for 274 direct light, was used to simulate the trajectory of the sun, and the directions were 275 dependant of the location (latitude, longitude), the day of the year, and on the time 276 step used for the sun course discretization (approx. 25 directions in this work). 277 Each of these directions was associated with a weighting coefficients derived from 278 the Standard Over Cast (SOC) distribution of sky radiance (Moon and Spencer 279 1942). The porosity is directly the ratio of transmitted light to incident light, a 280 value of 1 means that all light goes through while a value of 0 means that no light 281 goes through. The grey-level image constituted by the beam porosity values is 282 therefore a shadow map of the canopy transmittance. For each defined direction, 283 M $\mu$ SLIM was used to compute the opacity values of the beams and to produce 284 such an image in a plane orthogonal to the light. To ensure both results precision 
285 and fast computation, a lineic density of 150 was used for the beam sampling (Da

286 Silva et al., 2008), thus generating $150 \times 150$ pixels images. The images were

287 then projected on the ground and rotated according to the light directions azimuth.

288 Images from each set of incoming radiation directions were merged by using the

289 weighting coefficients producing two intermediate images, one for the integrated

290 transmittance of diffuse light and one for the direct light. Finally, these two

291 images were merged using the diffuse to total ratio, $D / G$, measured from the extra

292 sensor in the field. The grey-level values of pixels, from 0 (black) to 1 (white),

293 represented the transmittance classes simulated by M $\mu$ SLIM. The simulated light

294 transmittance of the central zone could then be compared to the field 295 measurements.

\section{Virtual experiments}

298 To assess the effect of the deterioration of canopy description on the simulated

299 light histogram, we generated five different types of mockups for each stand with

300 decreasing amount of information on canopy architecture.

301 1. The asymmetric mockup where all available dendrometric data are used to 302 generate asymmetric crowns.

3032 . The simple mean mockup where crowns are represented by simple 304 geometric shapes, cones for pines, spheres otherwise, and where the radius 305 of each shape is the mean of the measured radii.

306 3. The simple max mockup where crowns are represented by simple 
geometric shapes, cones for pines, spheres otherwise, and where the radius of each shape is the maximum of the measured radii.

4. The allometric radius mockup where crowns are represented by simple geometric shapes, cones for pines, spheres otherwise, and where the radius of each shape is obtained from allometric relation with $\mathrm{DBH}$.

5. The allometric mockup where crowns are represented by simple geometric shapes, cones for pines, spheres otherwise, and where the radius of each shape and the height of cones are obtained from allometric relation with $D B H$.

316 For every type of mockup, the values for the height of crown base and for the 317 height of the cones (except for the allometric type) are the measured ones.

318 Allometric relations were defined as linear model between DBH and mean radius

319 and, for pines, between $\mathrm{DBH}$ and height. The relations obtained from field 320 measurements data are described in Tab.2, and Fig.2 shows 3D reconstructions 321 using two different types of crown shapes.

322 To complement the attenuation effect of the buffer zone for low elevation 323 radiations, it was necessary to add an artificial cylindrical wall surrounding the 324 zone of interest. The wall was centered on the zone of interest with a radius of the 325 zone of interest size. The height of the wall was set to the mean base crown height 326 of trees in the zone of interest. The coefficient of transmission of the wall (i.e. 327 wall opacity) was calibrated using in silico simulation experiments with the stands 328 of one site and then validated using the other stands from independent sites. 
329 Adequacy of this method will be discussed further on.

\section{Model estimation}

332 The model outputs were qualitatively and quantitatively compared to experimental 333 data. The qualitative estimations were carried out by comparing the light 334 transmittance Cumulative Distribution Functions (CDF) to determine over- and/or 335 under-represented light transmittance class. The quantitative estimations were 336 achieved with the Kolmogorov-Smirnov test (K-S test) and the absolute 337 discrepancy index, AD (Gregorius 1974; Pommerening 2006). The K-S test is a 338 non-parametric test for the equality of continuous, one-dimensional probability 339 distributions that can be used to compare two samples. It quantifies the maximum 340 distance between the empirical CDF of two samples. The null distribution of this

341 statistic is calculated under the null hypothesis that the samples are drawn from

342 the same distribution. The p-value of the K-S test represents the $\alpha$ level at which 343 the null hypothesis can be rejected (i.e. a p-value $>0.1$ means that the null 344 hypothesis cannot be rejected at $10 \%$ or lower level).

345 The absolute discrepancy index is defined as:

$$
A D=\frac{1}{2} \sum_{i=1}^{n}\left|s_{i}-s_{i}^{\prime}\right| \quad A D \in[0,1]
$$

346 where $\mathrm{n}$ is the number of classes, $s_{i}$ is the relative frequency in class $\mathrm{i}$ of the first

347 distribution, and $s_{i}^{\prime}$ is the relative frequency in class $\mathrm{i}$ of the second distribution.

$348 \mathrm{AD}$ is defined as the relative proportion that needs to be exchanged between the 
349 classes if the first distribution were to be transformed into the second distribution.

350 Correspondingly, 1-AD is the proportion common to both distributions, a value of

$351 \mathrm{AD}=1$ means that both distributions have no common class, whereas $\mathrm{AD}=0$

352 signifies that the distributions are absolutely identical (Pommerening 2006).

353 Both quantitative analysis were carried out with light measurements as reference

354 values and the results are shown in Tab.3.

\section{Results}

357 The comparison between the CDF of the measured light transmittance and the

358 ones obtained with the different mockups, as shown in Fig.3, were used to

359 qualitatively assess the quality of the model prediction and the effect of

360 deterioration of crown shape description. The CDF provides an alternate

361 representation to light transmittance histograms that facilitates comparison

362 between different distributions. The importance of a specific light transmittance

363 class is given by the slope of the CDF at that point, i.e. a non represented class

364 will yield a null slope and the more substantial the class, the steeper the slope

365 (Fig. 3). The classes of high importance will be titled as main classes whereas the 366 classes of low significance will be designated as minor classes.

368 Simulation with asymmetric mockups

369 The light model using the asymmetric mockups was able to simulate light

370 transmission distribution similar to the measurement with a level of confidence of 
371 the K-S test above 5\% for all stands except Fonfreyde5 (3\%) and Fonfreyde1

$372(<1 \%)$. In that case, the mean comparison yielded a statistically significant

373 difference for the same two stands. However, the AD values were below 0.3 for

374 all stands with a mean of 0.21 (Tab.3).

375 In the case of Fonfreyde1, the measured transmitted light were almost evenly 376 distributed in only two light transmittance classes, [0-5] and [5-10]. The simulated

377 distribution showed the same two main classes with an unbalance in favor of the

378 [0-5] class. Although the p-value of the K-S test allowed to reject the hypothesis

379 that the measured and simulated light distribution were similar, the AD value was

380 below the mean value of all stands. The simulated transmittance of Fonfreyde2

381 were almost identical to the measured ones despite the missing [0-5] class in the

382 simulation (i.e. simulated CDF slope is null through entire [0-5] class). The best

383 values for both the p-value and $\mathrm{AD}$ were obtained for this stand. In the case of

384 Fonfreyde3 the difference in the standard deviation (Tab.3) between the measured 385 and simulated light distributions was a good indicator of the fact that the lower 386 and higher classes, [15-25] and [50-60] respectively, were not simulated to the 387 profit of the median classes [30-40] as shown by the Asymmetric CDF being 388 below and then above the CDF of measurements. On the contrary, in the case of 389 Fonfreyde5, the Asymmetric CDF started below and ended above the 390 measurement one, indicating that the median classes ([10-20]) were under 391 simulated to the benefit of the [30-35] class that did not appear in the 392 measurements and the [5-10] one that have very low substance. The highest AD 
393 values were obtained for these two stands.

394 The simulated distributions for Lorris38 correctly rendered both the main and 395 minor classes with, however, a less pronounced peak for the [5-10] class 396 expressed by the more abrupt slope of the measured CDF. There were no missing 397 or extra classes simulated and the AD was just above the mean value. Similarly to 398 Lorris38, the main and minor classes of Lorris 255 were correctly simulated 399 without any missing or extra classes. Within each group, main and minor, some 400 classes were under-represented to the benefit of the over-represented ones. 401 However these discrepancies were subsidiary as the very high p-value and the 402 below-the-mean $\mathrm{AD}$ attest. In the case of VentouxC7, the simulated distribution 403 reproduced the bell-shape of the measured one but with slightly heavier tails due 404 to the two extra classes on the sides of the distribution, [35-40] and [65-70]. Note 405 that the isolated [10-15] measured class was not simulated, as shown by the 406 advent of a proportion difference between measurements and simulation. 407 Similarly to Lorris255, a high p-value and a low AD were observed despite of 408 these differences. Finally, the simulated distribution for Ventoux34, whereas 409 correctly simulating the two main classes, [0-5] and [5-10] accounting for almost $41070 \%$ of the transmittance distribution, increased the unbalance between them in 411 favor of the lowest one. The minor classes were adequately simulated but without 412 respecting the discontinuity shown in the measurements as indicated by the above413 mean AD. 
415 Simulation with the simple mean mockups

416 Replacing the asymmetric by the simple mean mockups significantly reduced the

417 p-values of the KS test, except for Fonfreyde1 and Fonfreyde3, but yielded AD

418 values below 0.3, except for Fonfreyde5 and VentouxC7, that were similar to the

419 ones obtained with the asymmetric mockups as shown by the slight increase of the

420 mean $\mathrm{AD}$ to 0.24 . The principal effect of this change of crown shape on the

421 distributions of light transmittance compared to the distributions obtained with the

422 asymmetric crowns was to reduce the most represented classes to the benefit of

423 the minor ones. This was comparable to the crushing effect obtained on a

424 Gaussian function by increasing its variance parameter. The variance increase was

425 indeed observed for all stands but Lorris 255 and interestingly, the two sample t-

426 test indicated statistically significant differences for Fonfreyde5, VentouxC7 and

427 Lorris 255 . This effect actually benefited Fonfreyde1, Fonfreyde3 and Lorris 38

428 simulation results. The p-value increased and AD decreased significantly for

429 Fonfreyde1 and Fonfreyde3, whereas for Lorris38, both values decreased.

431 Simulation with the simple max mockups

432 The simple max approach yielded light transmittance distributions that were

433 significantly shifted to the lower transmittance classes, i.e. left shifted CDF (Fig.

434 3). This effect was visible on the simulation results of all stands but was less

435 pronounced for Fonfreyde 3 and VentouxC7. The dramatic increase of the AD

436 mean value to 0.6 well illustrated this behavior but mean comparison was 
437 sufficient to assess the importance of the discrepancies.

439 Simulation with allometric mockups

440 The use of the allometric radius and allometric mockups yielded similar results as

441 illustrated by comparable means and variances and similar mean AD values, 0.345

442 and 0.333 , respectively. The effect of this change of crown shape on the

443 distributions of light transmittance was similar to the simple mean effect with the

444 addition of a slight shift toward higher transmittance classes, indicated by right

445 shifted CDF (Fig. 3). The p-values were significantly reduced except for

446 Fonfreyde1, Fonfreyde5 and Ventoux34, but only for Fonfreyde1 this increase of

447 the p-value was associated with a decrease of AD (Tab.3).

449 Comparison between all simulations

450 The AD results (Fig.4) show that the asymmetric mockups yielded the

451 distributions closest to the measurement, the simple mean approach deteriorated

452 slightly the results whereas the simple max approach had dramatic effect. Using

453 allometric crowns yielded results in between but closer to the simple mean ones.

454 These results confirmed the classification trend yielded by the two-sample t-test

455 analysis that showed no statistically significant differences between the

456 measurements and the asymmetric and simple mean approaches on one side,

457 between the two allometric approaches on the other side and showed the 458 segregation of the simple max one. 


\section{Statistical considering}

463 Our study on the impact of the deterioration of the accuracy of crown

464 representation on simulated light transmission highlighted some statistical issues.

465 In spatially explicit transmittance models, a spatially point to point comparison

466 approach between measured and modeled transmittance generally shows little

467 agreement because small errors in crown location, often coming from errors

468 during field measurements, yields large local differences in transmittance

469 (Mariscal et al. 2004), particularly when the proportion of direct radiation is

470 important (Groot et al. 2004). However only considering a mean and variation

471 around this mean (e.g. SD) could lead to some errors (e.g. underestimation of area

472 fully lighted) due to distribution non centered on mean with sometimes a long tail

473 or several modes. To avoid this problem we compared the simulated distribution

474 of light transmittance to the measured ones using two different non parametric

475 descriptors, the K-S test and the AD index.

476 Although commonly used, and mathematically well-founded, the K-S test showed

477 some limitations when applied to peculiar distributions as the one from

478 Fonfreyde1. The problem stems directly from the test definition where the

479 accordance between two distributions is based on the maximum distance between

480 the CDFs. When the distribution shows very low dispersion, a small difference in 
481 distribution can yield a big maximum distance between CDFs and therefore a 482 rejection of the null-hypothesis from K-S test. On the contrary, the AD index that 483 measures the changes required to transform one distribution into the other is 484 robust in regard of the distribution dispersion. Even though AD is very well suited 485 to quantify the difference between distributions or to classify results, the AD value 486 is not associated with any confidence index. Hence it is up to the user to define the 487 threshold under which distributions will be considered similar. Consequently, 488 combining the use of the K-S test and the AD index allowed us to accurately 489 compare and assess the differences between simulated and measured light 490 distributions.

492 Model evaluation

493 The goal of the present study was not to validate, stricto sensus, the model

494 M $\mu$ SLIM. Such an evaluation would require an independent data set of light and 495 tree measurements. Our objective was to evaluate the quality of light predictions 496 with increasing deterioration of the crown description. However the comparison 497 of light measurements (with 64 sensors regularly distributed on a square grid in 498 the plot) and the simulation with full asymmetric crown description (i.e. crown 499 radius extension in 4 to 8 directions + crown height and length) showed the good 500 quality of simulated light distribution (K-S p-value $>0.10$ or $\mathrm{AD}<0.3$ ). Results 501 are in the range of models using similar scales of description (e.g. Brunner 1998; 502 Cescatti 1997; Gersonde et al. 2004; Groot 2004; Mariscal et al. 2004; Stadt and 
503 Lieffers 2000).

504 As pointed out by Norman and Welles (1983), the computation of beam path

505 lengths is a crucial procedure. Due to the multi-scale design of M $\mu$ SLIM, in 506 addition to the possibility of using any type of envelope, an analytical resolution 507 as proposed by Norman and Welles (1983) or Cescatti (1997) was not an option.

508 This task was instead performed by ray tracing algorithms that determine and 509 analyse the path of each cast ray among the canopy crown shapes (Wang and 510 Jarvis, 1990). With the ever increasing computational power of graphic cards 511 available to high level operations, this formerly time consuming procedure can 512 now be executed for many direction without impairing the model performances.

514 To avoid the problem of low elevation angles; i.e. interception of light by very far 515 elements close to the horizon in the field, whereas not represented in the model, 516 we had to come up with an alternative to the classical solution of canopy 517 duplication or projection on torus. These approaches are based on the strong 518 assumption of canopy homogeneity ; using them with our strongly heterogeneous 519 stands would introduce a non controlled approximation that would, in turn, induce 520 bias in the results interpretation. Instead we chose to estimate the radiative 521 parameters of the surrounding environment using an inverse modeling approach 522 through the addition of an opaque wall. The wall opacity was calibrated using 523 Fonfreyde stands data with full asymmetric crown description. The value was then 524 used as a parameter to run the simulations for the stands from the two other 
525 independent sites at the same level of crown description. Finally, the model

526 predictions were compared to the field light measurements. The results suggest

527 that the coefficient of transmission of the wall properly represented the radiative

528 properties of the environment, at least for low elevation angles. Moreover,

529 considering our objective, the opaque wall approach provided a simple solution

530 saving significant computational time otherwise required by the canopy

531 duplication. This approach seems thus promising and simple to set-up but would

532 benefit from more complete sensitivity analysis, in particular on wall size or

533 position.

534 One interest of our model is that crown porosity is simply estimated by a vertical

535 photograph of tree crown (extension of the method of Canham et al. 1999) and

536 seems to support accurate results in light distribution; however the extent to which

537 this parameter influenced the results needs to be more adequately studied. As

538 pointed out by Stadt and Lieffers (2000) determination of leaf and shading

539 elements (branch, trunk) is often critical in light transmission modeling.

541 Effects of crown description deterioration

542 Our results corroborate that differences in crown shape and size is a key

543 determinant of light transmittance as stated by Vieilledent et al. (2010). Moreover,

544 this study confirmed the importance of crown shape when simulating spatialized

545 light transmittance and endorse the sensitivity to variations in the crown geometry

546 parameters, especially the crown radius parameter, as already reported (Beaudet et 
547 al. 2002; Brunner 1998; Cescatti 1997). However a crown mean radius with

548 crown height and spatialization seem to be a good alternate (Courbaud et al. 2003)

549 to detailed measures (i.e. measurement of crown extension in 4 to 8 directions)

550 even though simple shape like spheres and cones are known to be inadequate

551 (Mariscal et al. 2004). Other shapes should be tested, more in relation with tree

552 species architecture. Simplifying the crown representation in the tRAYci model to

553 average values for species and canopy strata resulted in little reduction in the

554 model performance (Gersonde et al. 2004). Describing tree crown extension with

5554 to 8 radius is typically non feasible in practice in management or inventory 556 operations, whereas assessing mean crown diameter may be acceptable in some 557 cases. Therefore an approach that starts with simple shapes that can later be 558 deformed using an optimization process (Boudon and Le Moguedec 2007; Piboule 559 et al. 2005) should be considered in further studies. Indeed previous studies 560 showed the importance of crown asymmetric plasticity in response to local light 561 availability and space, among other factors (Vieilledent et al. 2010 and references 562 in it).

564 However using an Allometric approach would be more comfortable. The problem 565 is that the use of relationships between tree DBH and crown diameter or crown 566 height often decreased transmittance distribution prediction, whereas not for all 567 stands. With the allometric approach, the model generated smaller crown than 568 simple mean, thus same effect with shift to higher transmittance. We only tested 
569 linear relationships and non-linear functions could have led to slightly better

570 results (Beaudet et al. 2002) ; however many authors pointed out that the

571 predictive functions for crown radius from e.g. DBH has proved elusive (Stadt et

572 al. 2000) as they are often highly affected by uncontrolled factors such as climate

573 hazards, stand density, or thinning operations (as probably reflected in the

574 Fontfreyde's plots). There is often a high variability in tree allometry from an

575 individual to another (Vieilledent et al. 2010). Actually the $\mathrm{R}^{2}$ of the relationships

576 linking crown diameter to trunk diameter in that study are not excellent but in the

577 range of those commonly found in other studies (e.g. about 0.7 in Pinno et al.

5782001 or Pukkala et al. 1993).

580 Effects of the stand complexity

581 High light variability is generally recorded in forests due to temporal variations of 582 the sun path and heterogeneous spatial arrangement of light intercepting elements 583 in irregular and/or mixed stands (Courbaud et al. 2003; Pukkala et al. 1993). In 584 stands with a clumped structure (i.e. tree clumps alternating with large gaps), only 585 an approach at tree scale with spatialization can correctly predict transmittance, 586 whereas in dense stands, a Beer-Lambert law can be applied at the stand canopy 587 scale (Balandier et al., 2010). It is however important to note that in dense stands, 588 importance of small gaps within tree crowns due to different causes (diseases, 589 broken branches, not taken into account in the simulation) can lead to noticeable 590 differences as such of Fontfreyde 1 (Fig.3) (Beaudet et al. 2002). Low density 
591 stands Fonfreyde 3 and VentouxC7 are less affected by the simple max approach

592 probably because the crown "increase" is not enough to fill the 'big' gaps in the

593 canopy. Problems of crown overlaps, in fact very difficult to quantify in the field,

594 are also probably less critical than in dense stands.

595 As already pointed out by Courbaud et al. (2003) or Balandier et al. (2010) the 596 problem is that it is very difficult to generalize results recorded on a site for a 597 particular stand structure to other sites or stands with other species or structures.

598 This argues in favor of studying the effect of stand structure in interaction with the 599 scale of stand description; this could be done for instance by the use of point 600 process analysis.

601

\section{Acknowledgements}

603 The authors would like to thank for their help, in the field or for information on

604 the stands, Catherine Menuet, Gwenael Philippe, Philippe Dreyfus, and Yann 605 Dumas.

606

607

\section{Funding}

608 The study was partly supported by the French program "ECOGER", sustainable 609 management of mixed forests.

610

\section{References}

612 Adam B, Benoît JC, Balandier P, Marquier A, Sinoquet H (2006) PiafPhotem - 
613 software for thresholding hemispherical photographs. Version 1.0. UMR PIAF

614 INRA-UBP, Clermont-Ferrand - ALLIANCE VISION Montélimar, France.

615

616 Balandier P, Collet C, Miller JH, Reynolds PE, Zedacker SM (2006a) Designing

617 forest vegetation management strategies based on the mechanisms and dynamics

618 of crop tree competition by neighbouring vegetation. Forestry 79, 1: 3-27.

619

620 Balandier P, Marquier A, Dumas Y, Gaudio N, Philippe G, Da Silva D, Adam B,

621 Ginisty C, Sinoquet H (2009) Light sharing among different forest strata for

622 sustainable management of vegetation and regeneration. In: Orlovic S (ed)

623 Forestry in achieving millennium goals, Institute of lowland forestry and

624 environment, Novi-Sad, Serbia, pp 81-86.

625

626 Balandier P, Marquier A, Perret S, Collet C, Courbeau B (2010) Comment estimer

627 la lumière dans le sous-bois forestier à partir des caractéristiques dendrométriques

628 des peuplements. Rendez-Vous Techniques ONF 27-28: 52-58.

629

630 Balandier P, Sonohat G, Sinoquet H, Varlet-Grancher C, Dumas Y (2006b)

631 Characterisation, prediction and relationships between different wavebands of

632 solar radiation transmitted in the understorey of even-aged oak (Quercus petraea,

633 Q. robur) stands. Trees 20: 363-370.

634 
635 Bartelink HH (1998) Radiation interception by forest trees: a simulation study on

636 effects of stand density and foliage clustering on absorption and transmission.

637 Ecol Model 105: 213-225.

638

639 Beaudet M, Messier C, Canham C (2002) Predictions of understorey light

640 conditions in northern hardwood forests following parameterization, sensitivity

641 analysis, and tests of the SORTIE light model. For Ecol Manage 165: 235-248.

642

643 Boudon F, Le Moguedec G (2007) Déformation asymétrique de houppiers pour la

644 génération de représentations paysagères réalistes. Revue Electronique

645 Francophone d'Informatique Graphique (REFIG) 1, 1.

646

647 Brunner A (1998) A light model for spatially explicit forest stand models. For

648 Ecol Manage 107: 19-46.

649

650 Canham C, Coates KD, Bartemucci P, Quaglia S (1999) Measurement and

651 modeling of spatially explicit variation in light transmission through interior

652 cedar-hemlock forests of British Columbia. Can J For Res 29: 1775-1783.

653

654 Cescatti A (1997) Modelling the radiative transfer in discontinuous canopies of

655 asymmetric crowns. I. Model structure and algorithms. Ecol Model 101: 263-274.

656 
657 Cescatti A (1997) Modelling the radiative transfer in discontinuous canopies of

658 asymmetric crowns. II. Model testing and application in a Norway spruce stand.

659 Ecol Model 101: 275-284.

660

661 Chen JM, Black TA (1992) Defining leaf area index for non-flat leaves. Plant Cell

662 Env 15: 421-429.

663

664 Courbaud B, de Coligny F, Cordonnier T (2003) Simulating radiation distribution

665 in a heterogeneous Norway spruce forest on a slope. Agr For Meteor 116: 1-18.

666

667 Da Silva D (2008) Caractérisation de la nature multi-échelles des plantes par des

668 outils de l'analyse fractale, application à la modélisation de l'interception de la

669 lumière. Dissertation, University of Montpellier, France.

670

671 Da Silva D, Boudon F, Godin C, Sinoquet H (2008) Multiscale Framework for

672 Modeling and Analyzing Light Interception by Trees. Multiscale Modeling \&

673 Simulation 7: 910-933.

674

675 Den Dulk JA (1989) The interpretation of Remote Sensing, a feasibility study.

676 Dissertation, University of Wageningen, The Netherlands.

677

678 Gaudio N, Balandier P, Dumas Y, Ginisty C (2011) Growth and morphology of 
679 three forest understorey species (Calluna vulgaris, Molinia caerulea and

680 Pteridium aquilinum) according to light availability. For Ecol Manage 261: 489-

681498.

682

683 Gersonde R, Battles JJ, O'Hara KL (2004) Characterizing the light environment in

684 Sierra Nevada mixed-conifer forests using a spatially explicit light model. Can J

685 For Res 34: 1332-1342.

686

687 Gregorius HR (1974) Genetischer Abstand zwischen Populationen. I. Zur

688 Konzeption der genetischen Abstandsmessung (Genetic distance among

689 populations. I. Towards a concept of genetic distance measurement). Silvae

690 Genetica 23: 22-27.

691

692 Groot A (2004) A model to estimate light interception by tree crowns, applied to

693 black spruce. Can J For Res 34: 788-799.

694

695 Hale SE, Edwards C, Mason WL, Price M, Peace A (2009) Relationships between

696 canopy transmittance and stand parameters in Sitka spruce and Scots pine stands

697 in Britain. Forestry 82, 5: 503-513.

698

699 Lieffers VJ, Messier C, Stadt KJ, Gendron F, Comeau PG (1999) Predicting and

700 managing light in the understory of boreal forests. Can J For Res 29: 796-811. 
702 Mariscal MJ, Martens SN, Ustin SL, Chen J, Weiss SB, Roberts DA (2004) Light-

703 transmission profiles in an old-growth forest canopy: simulation of

704 photosynthetically active radiation by using spatially explicit radiative transfer

705 models. Ecosystems 7: 454-467.

706

707 Monsi M, Saeki T (1953) Uber den Lichtfaktor in den Pflanzengesellschaften und

708 seine Bedeutung fur die Stoffproduktion. Japanese Journal of Botany 14: 22-52

709

710 Moon P, Spencer DE (1942) Illumination from a non-uniform sky. Transactions

711 of the Illumination Engineering Society 37.

712

713 Myneni RB, Ross J, Asrar G (1989) A review on the theory of photon transport in

714 leaf canopies. Agr For Meteor 45:1-153

715

716 Norman J.M., Welles J.M. (1983) Radiative Transfer in an array of Canopies.

717 Agronomy Journal 75: 481-488.

718

719 Perrin H (1963) Sylviculture. Ecole Nationale des Eaux et des Forêts, Nancy,

720 France, Tome 1, p 174.

721

722 Pinno BD, Lieffers VJ, Stadt KJ (2001) Measuring and modelling the crown and 
723 light transmission characteristics of juvenile aspen. Can J For Res 31: 1930-1939.

725 Pommerening A (2006) Evaluating structural indices by reversing forest structural 726 analysis. For Ecol Manage 224: 266-277.

728 Pradal C, Dufour-Kowalski S, Boudon F, Fournier C, Godin C (2008) OpenAlea:

729 a visual programming and component-based software platform for plant

730 modelling. Funct Plant Biol 35.

732 Pukkala T, Kuuluvainen T, Stenberg P (1993) Below-canopy distribution of

733 photosynthetically active radiation and its relation to seedling growth in a boreal

734 Pinus sylvestris stand. Scand J For Res 8: 313-325.

735

736 Ross J (1981) The radiation regime and the architecture of plant stands. The

737 Hague, The Netherlands.

738

739 Sillion FX, Puech C (1994) Radiosity and Global Illumination. The Morgan

740 Kaufmann Series in Computer Graphics, Morgan Kaufmann Inc. San Francisco,

741 California, USA

742

743 Sinoquet H, Stephan J, Sonohat G, Lauri PE, Monney P (2007) Simple equations

744 to estimate light interception by isolated trees from canopy structure features: 
745 assessment with three-dimensional digitized apple trees. New Phytol 175: 94-106.

746

747 Song C, Band LE (2004) MVP: a model to simulate the spatial patterns of

748 photosynthetically active radiation under discrete forest canopies. Can J For Res

749 34: 1192-1203.

750

751 Sonohat G, Balandier P, Ruchaud F (2004) Predicting solar radiation

752 transmittance in the understory of even-aged coniferous stands in temperate

753 forests. Ann For Sci 61: 629-641.

754

755 Stadt KJ, Lieffers VJ (2000) MIXLIGHT: a flexible light transmission model for

756 mixed-species forest stands. Agr For Meteor 102: 235-252.

757

758 Stenberg P (2006) A note on the G-function for needle leaf canopies. Agr For

759 Meteor 136: 76-79.

760

761 Tardieu F (2010). Why work and discuss the basic principles of plant modeling 50

762 years after the first plant models? J. Exp. Bot., 61:2039-2041.

763

764 Vieilledent G, Courbaud B, Kunstler G, Dhôte JF, Clark JS (2010) Individual

765 variability in tree allometry determines light resource allocation in forest

766 ecosystems: a hierarchical Bayesian approach. Oecologia 163: 759-773. 
768 Wang YP, and Jarvis PG (1990) Description and validationof an array model 769 MAESTRO. Agr For. Meteor 51: 257-280. 


\section{Tables}

Table 1: Plot description. Each plot was approximately $50 \mathrm{~m} \times 50 \mathrm{~m}$

\begin{tabular}{|c|c|c|c|c|c|c|c|c|c|}
\hline Site & $\begin{array}{c}\text { Latitude } \\
\text { Longitude }\end{array}$ & $\begin{array}{c}\text { Ele vation } \\
\text { (m) }\end{array}$ & $\begin{array}{c}\text { Density } \\
\left(\text { stem ha }^{-1}\right)\end{array}$ & $\begin{array}{l}\text { Mean Height } \\
\text { (m) (Min- } \\
\text { Median-Max) }\end{array}$ & $\begin{array}{c}\text { D.B.H. } \\
\text { (cm) (Min- } \\
\text { Median-Max) }\end{array}$ & $\begin{array}{c}\text { Basal area } \\
\left(\mathrm{m}^{2} \mathrm{ha}^{-1}\right)\end{array}$ & Tree species & $\begin{array}{c}\text { Basal area } \\
(\%)\end{array}$ & Opacity \\
\hline \multirow{3}{*}{ Fonfreyde 1} & \multirow{3}{*}{$\begin{array}{l}47^{\circ} 42^{\prime} \mathrm{N} \\
02^{\circ} 58^{\prime} \mathrm{E}\end{array}$} & \multirow{3}{*}{920} & \multirow{3}{*}{2353} & 7.3 & 7 & \multirow{3}{*}{54} & Pinus sylvestris & 99.4 & 0.835 \\
\hline & & & & 14.5 & 16 & & Other species & \multirow[t]{2}{*}{0.6} & \multirow[t]{2}{*}{$0.75-0.86$} \\
\hline & & & & 18.4 & 33 & & & & \\
\hline \multirow{3}{*}{ Fonfeyde2 } & \multirow{3}{*}{$\begin{array}{l}47^{\circ} 42^{\prime} \mathrm{N} \\
02^{\circ} 58^{\prime} \mathrm{E}\end{array}$} & \multirow{3}{*}{920} & \multirow{3}{*}{1103} & 7.2 & 7 & \multirow{3}{*}{33} & Pinus sylvestris & 73.6 & 0.835 \\
\hline & & & & 14.5 & 17 & & Other species & \multirow[t]{2}{*}{26.4} & \multirow{2}{*}{$0.75-0.86$} \\
\hline & & & & 18.3 & 42 & & & & \\
\hline \multirow{3}{*}{ Fonfreyde 3} & \multirow{3}{*}{$\begin{array}{l}47^{\circ} 42^{\prime} \mathrm{N} \\
02^{\circ} 58^{\prime} \mathrm{E}\end{array}$} & \multirow{3}{*}{920} & \multirow{3}{*}{563} & 6.3 & 9 & \multirow{3}{*}{22} & Pinus sylvestris & 90.4 & 0.835 \\
\hline & & & & 14.2 & 21 & & Other species & \multirow[t]{2}{*}{9.6} & \multirow[t]{2}{*}{$0.75-0.86$} \\
\hline & & & & 18.2 & 37 & & & & \\
\hline \multirow{3}{*}{ Fonfreyde 5} & \multirow{3}{*}{$\begin{array}{l}45^{\circ} 41^{\prime} \mathrm{N} \\
02^{\circ} 59^{\prime} \mathrm{E}\end{array}$} & \multirow{3}{*}{910} & \multirow{3}{*}{710} & 11.3 & 9 & \multirow{3}{*}{42} & Pinus sylvestris & 96.2 & 0.835 \\
\hline & & & & 18.3 & 28 & & Other species & \multirow[t]{2}{*}{3.8} & \multirow{2}{*}{$0.75-0.86$} \\
\hline & & & & 23 & 43 & & & & \\
\hline \multirow{3}{*}{ Lorris 38} & \multirow{3}{*}{$\begin{array}{r}47^{\circ} 47^{\prime} \mathrm{N} \\
02^{\circ} 34^{\prime} \mathrm{E}\end{array}$} & \multirow{3}{*}{150} & \multirow{3}{*}{664} & 4 & 7 & \multirow{3}{*}{32} & Pinus sylvestris & 56.7 & 0.79 \\
\hline & & & & 16.1 & 17 & & Quercus petraea & 34.2 & 0.867 \\
\hline & & & & 29.3 & 71 & & Other species & 9.1 & $0.75-0.86$ \\
\hline \multirow{3}{*}{ Lorris 255} & \multirow{3}{*}{$\begin{array}{l}47^{\circ} 49^{\prime} \mathrm{N} \\
02^{\circ} 26^{\prime} \mathrm{E}\end{array}$} & & & 3.7 & 7 & & Pinus sylvestris & 36.7 & 0.79 \\
\hline & & 150 & 607 & 17 & 19 & 24 & Quercus petraea & 57.5 & 0.867 \\
\hline & & & & 22.3 & 47 & & Other species & 5.8 & $0.75-0.86$ \\
\hline
\end{tabular}


Table 2: Allometric relation between DBH and crown mean radius and height. Linear models of the form $a^{*} D B H+b$ were used for both mean radius and height

\begin{tabular}{|c|c|c|c|c|c|}
\hline & Tree species & Site & Slope (a) & Intercept (b) & $\mathrm{R}^{2}$ \\
\hline \multirow{12}{*}{ 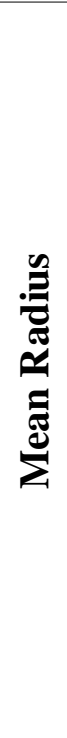 } & \multirow{3}{*}{ Pinus } & Fonfreyde & 2.62 & 13.91 & 0.72 \\
\hline & & Lorris & 2.29 & 50.64 & 0.57 \\
\hline & & Ventoux & 1.86 & 69.28 & 0.83 \\
\hline & Quercus petraea & Lorris & 2.73 & 129.69 & 0.60 \\
\hline & Fagus sylvatica & Ventoux & 3.98 & 75.56 & 0.82 \\
\hline & Acer opalus & Ventoux & 10.10 & 9.68 & 0.66 \\
\hline & \multirow{2}{*}{ Betula pendula } & Fonfreyde & 2.35 & 79.12 & 0.67 \\
\hline & & Lorris & 2.13 & 94.36 & 0.29 \\
\hline & Carpinus betulus & Lorris & 7.18 & 74.78 & 0.36 \\
\hline & Populus tremula & Lorris & 4.86 & 19.90 & 0.86 \\
\hline & \multirow{2}{*}{ Sorbus torminalis } & Lorris & 3.19 & 135.01 & 0.67 \\
\hline & & Ventoux & 2.88 & 85.38 & 0.71 \\
\hline \multirow{3}{*}{ } & \multirow{3}{*}{ Pinus } & Fontfreyde & 0.08 & 10.09 & 0.47 \\
\hline & & Lorris & 0.10 & 10.27 & 0.64 \\
\hline & & Ventoux & 0.12 & 2.25 & 0.93 \\
\hline
\end{tabular}


Table 3 Simulation results for the different mockups reconstruction. The p-value of the $K$-S test and the absolute discrepancy index (AD) were obtained with the measured light values as reference. Means with the same letter indicate that the difference between the means are not statistically significant at $\alpha=10 \%$ for an independent two-sample $t$-test.

\begin{tabular}{|c|c|c|c|c|c|c|c|}
\hline \multicolumn{2}{|c|}{ StandMMockup } & Measures & Asymmetric & Simple Mean & Simple Max & Allometric Radius & Allometric \\
\hline \multirow{4}{*}{ 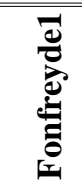 } & Mean & $5.15^{\mathrm{a}}$ & $4.19^{\mathrm{b}}$ & $5.06^{\mathrm{a}}$ & $0.44^{\mathrm{c}}$ & $4.29^{\mathrm{b}}$ & $4.14^{\mathrm{b}}$ \\
\hline & Std & 1.3 & 1.71 & 2.41 & 0.57 & 2 & 2.02 \\
\hline & $\mathrm{p}$-value & & $1.3 \mathrm{e}-5$ & $9.8 \mathrm{e}-3$ & $<1 \mathrm{e}-5$ & $7.1 \mathrm{e}-5$ & $3.1 \mathrm{e}-5$ \\
\hline & $\mathrm{AD}$ & & 0.203 & 0.063 & 0.516 & 0.141 & 0.172 \\
\hline \multirow{4}{*}{$\frac{\mathcal{O}}{0}$} & Mean & $14.7^{\mathrm{a}}$ & $14.69^{\mathrm{a}}$ & $15.72^{\mathrm{a}}$ & $7.19^{\mathrm{c}}$ & $21.37^{\mathrm{b}}$ & $20.32^{\mathrm{b}}$ \\
\hline & Std & 3.58 & 3.18 & 4.62 & 3.14 & 4.18 & 3.89 \\
\hline & $\mathrm{p}$-value & & 0.987 & 0.05 & $<1 \mathrm{e}-5$ & $<1 \mathrm{e}-5$ & $<1 \mathrm{e}-5$ \\
\hline & $\mathrm{AD}$ & & 0.078 & 0.219 & 0.75 & 0.594 & 0.531 \\
\hline \multirow{4}{*}{ 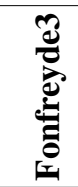 } & Mean & $38.08^{\mathrm{a}, \mathrm{b}}$ & $37.05^{\mathrm{a}}$ & $39.58^{\mathrm{b}}$ & $25.81^{\mathrm{c}}$ & $48.09^{\mathrm{d}}$ & $43.18^{\mathrm{e}}$ \\
\hline & Std & 9.46 & 5.73 & 8.66 & 9.3 & 7.71 & 7.35 \\
\hline & $\mathrm{p}$-value & & 0.08 & 0.52 & $<1 \mathrm{e}-5$ & $1.3 e-5$ & $9.8 \mathrm{e}-3$ \\
\hline & $\mathrm{AD}$ & & 0.281 & 0.234 & 0.453 & 0.406 & 0.329 \\
\hline \multirow{4}{*}{ 赵 } & Mean & $16.89^{a}$ & $19.29^{b}$ & $18.87^{\mathrm{b}, \mathrm{d}}$ & $9.52^{\mathrm{c}}$ & $16.81^{\mathrm{a}, \mathrm{b}, \mathrm{d}}$ & $18.32^{\mathrm{a}, \mathrm{d}}$ \\
\hline & Std & 4.37 & 6.68 & 7.94 & 6.35 & 7.43 & 8.32 \\
\hline & $\mathrm{p}$-value & & 0.03 & 0.017 & $<1 \mathrm{e}-5$ & $9.8 \mathrm{e}-3$ & 0.05 \\
\hline & $\mathrm{AD}$ & & 0.281 & 0.344 & 0.578 & 0.406 & 0.406 \\
\hline \multirow{4}{*}{ 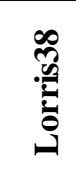 } & Mean & $8.43^{\mathrm{a}}$ & $8.41^{\mathrm{a}}$ & $8.61^{\mathrm{a}}$ & $0.645^{\mathrm{c}}$ & $15.79^{\mathrm{b}}$ & $16.09^{b}$ \\
\hline & Std & 6.85 & 5.54 & 5.99 & 1.31 & 7.66 & 7.91 \\
\hline & $\mathrm{p}$-value & & 0.126 & 0.029 & $<1 \mathrm{e}-5$ & $1.9 \mathrm{e}-5$ & $<1 \mathrm{e}-5$ \\
\hline & $\mathrm{AD}$ & & 0.219 & 0.172 & 0.781 & 0.344 & 0.359 \\
\hline \multirow{4}{*}{ 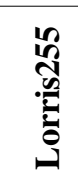 } & Mean & $20.8^{a}$ & $21.33^{\mathrm{a}}$ & $25.36^{\mathrm{b}}$ & $5.49^{c}$ & $21.1^{\mathrm{a}}$ & $21.1^{\mathrm{a}}$ \\
\hline & Std & 9.93 & 7.14 & 7.01 & 4.99 & 11.54 & 11.42 \\
\hline & $\mathrm{p}$-value & & 0.758 & 0.029 & $<1 \mathrm{e}-5$ & 0.16 & 0.203 \\
\hline & $\mathrm{AD}$ & & 0.172 & 0.25 & 0.844 & 0.281 & 0.266 \\
\hline \multirow{4}{*}{ 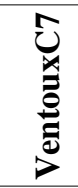 } & Mean & $53.34^{\mathrm{a}}$ & $54.3^{\mathrm{a}, \mathrm{b}}$ & $57.38^{\mathrm{d}}$ & $47.72^{c}$ & $55.66^{\mathrm{a}, \mathrm{b}}$ & $54.87^{\mathrm{b}, \mathrm{d}}$ \\
\hline & Std & 7.06 & 5.91 & 7.5 & 9.9 & 7.74 & 7.68 \\
\hline & $\mathrm{p}$-value & & 0.52 & $2 \mathrm{e}-4$ & $7 e-5$ & 0.005 & 0.017 \\
\hline & $\mathrm{AD}$ & & 0.172 & 0.359 & 0.375 & 0.266 & 0.281 \\
\hline \multirow{4}{*}{ 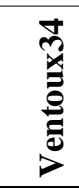 } & Mean & $12.25^{\mathrm{a}, \mathrm{b}}$ & $8.87^{\mathrm{a}}$ & $10.54^{\mathrm{a}}$ & $3.44^{\mathrm{c}}$ & $16.85^{b}$ & $17.05^{b}$ \\
\hline & Std & 15.29 & 11.35 & 13.52 & 7.9 & 19.59 & 19.74 \\
\hline & $\mathrm{p}$-value & & 0.05 & $9.8 \mathrm{e}-3$ & $<1 \mathrm{e}-5$ & 0.274 & 0.188 \\
\hline & $\mathrm{AD}$ & & 0.25 & 0.266 & 0.391 & 0.281 & 0.281 \\
\hline
\end{tabular}




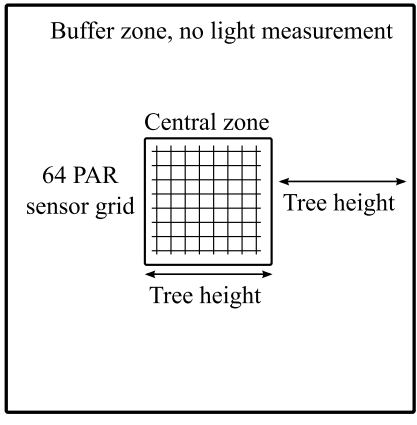

780 a.

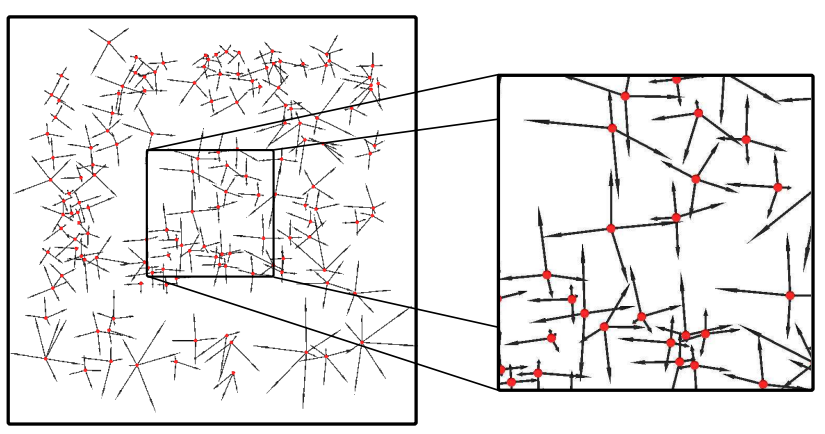

b.

c.

Figure 1: a. Experimental Unit. b. Field data: each dot locates a tree (its trunk), and each arrow defines a specific azimuth and distance from the trunk, characterizing the crown extend. $c$. Zoom in on the interest zone where light measurements where conducted. 


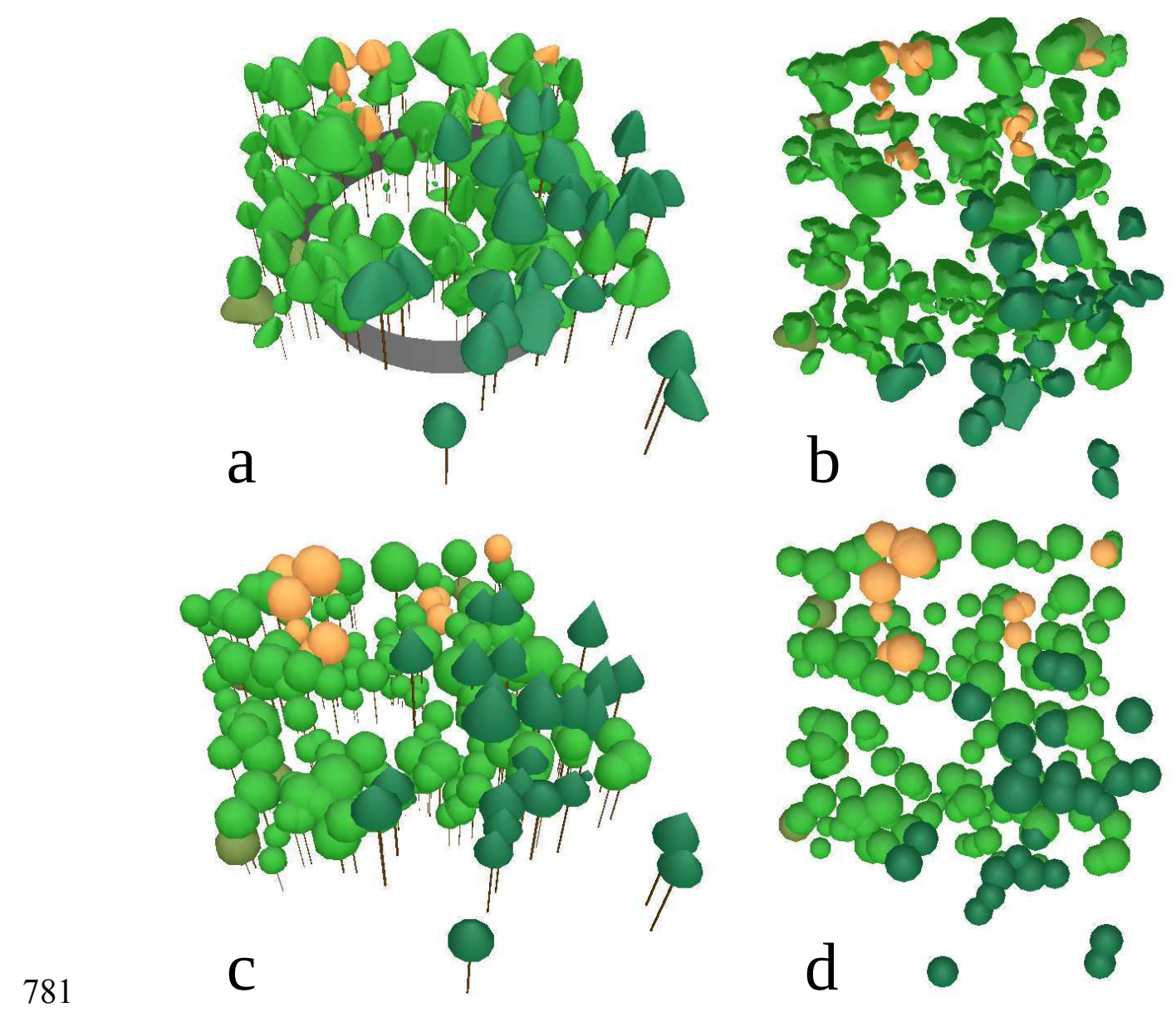

Figure 2: 3D reconstruction of the Lorris 255 experimental unit using the asymmetric crowns, side view( (a) and top view(b), and using the crowns from the allometric radius approach, side view (c) and top view(d).Colors are used to visually differentiate between tree species: dark green for pine (Pinus sylvestris L.), green for oak (Quercus petraea L.), orange for birch (Betula L.), and brown for hornbeam (Carpinus betulus L.)

782

783

784 

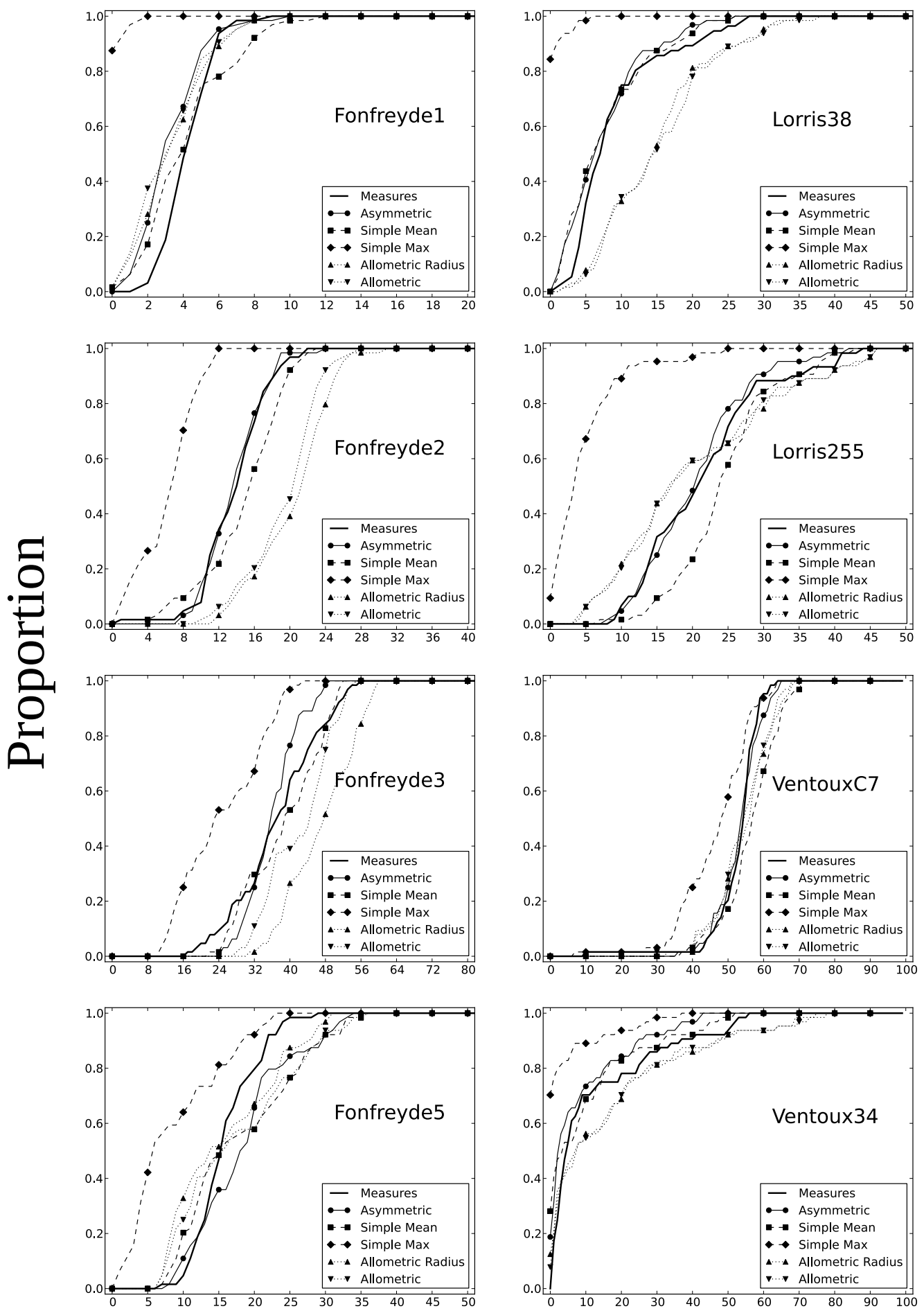
Figure 3: Cumulative Distribution Function $(C D F)$ of light transmittance for each stand and for every mockup type. Note that for legibility purpose the $x$-axis scale was adapted for each stand.

786

787

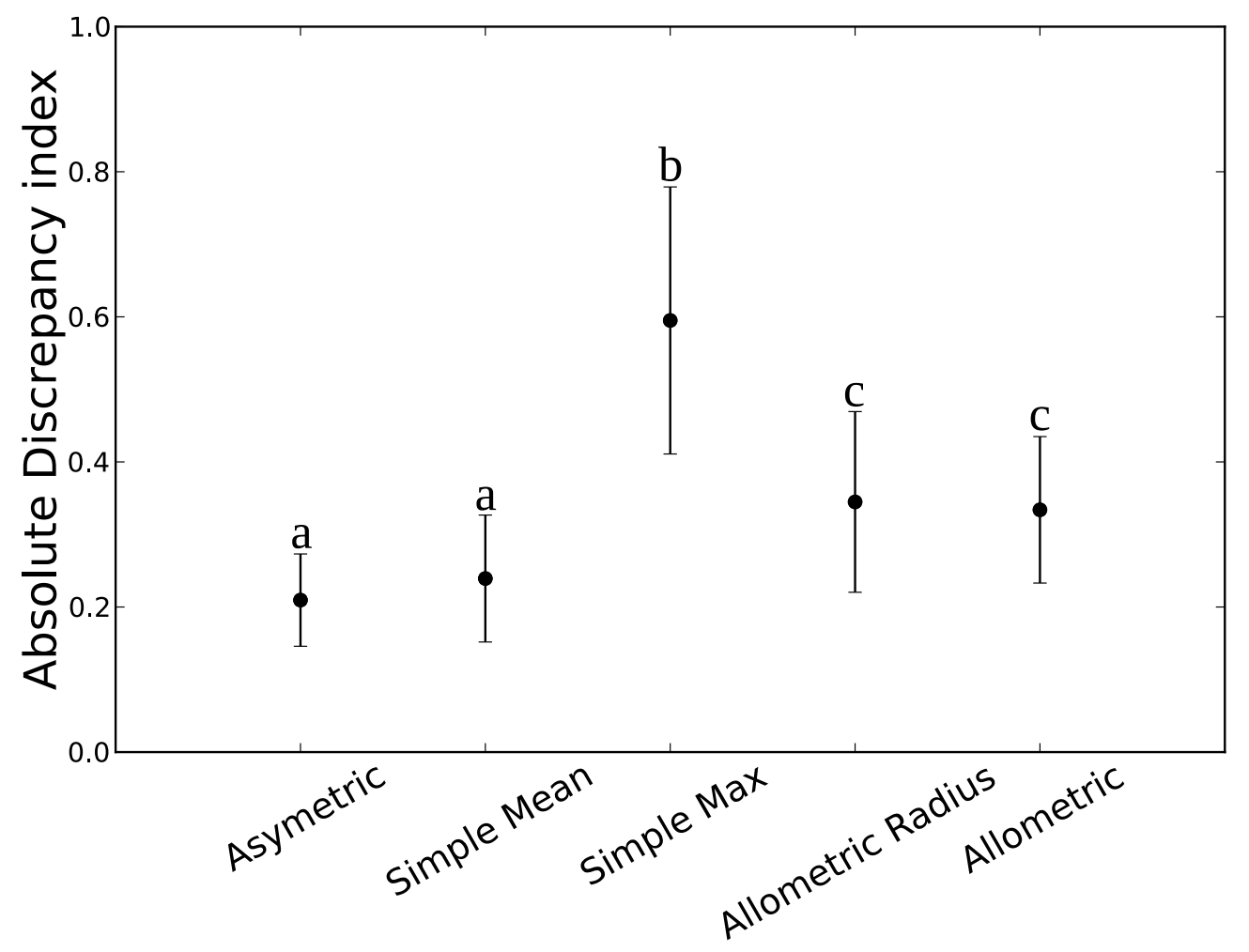

Figure 4: The points represent the mean of $A D$ calculated for each type of mockup over all stands, the bars being the standard deviation. Same letter above the bars indicate that the difference between the means are not statistically significant at $\alpha=10 \%$ for an independent two-sample t-test. 